\title{
The influence of multiple firing events on the formation and stability of activity patterns in continuous attractor networks
}

\author{
David Lyttle ${ }^{1 *}$, Alfredo Weitzenfeld ${ }^{4}$, Jean-Marc Fellous ${ }^{1,3}$, Kevin K Lin ${ }^{1,2}$ \\ From Twenty Second Annual Computational Neuroscience Meeting: CNS*2013 \\ Paris, France. 13-18 July 2013
}

Continuous attractor networks have been proposed to explain a variety of phenomena, including working memory and rodent entorhinal grid cells [1,2]. Typically, such networks consist of spatially-structured lattices of neurons in one or two dimensions with long-range inhibition and short-range excitation, which causes the network activity to spontaneously self-organize into one or more "bumps" of persistent activity. In two-dimensions, the activity patterns often take the form of triangular lattices, which bear a striking resemblance to the spatial patterns observed in recordings of entorhinal grid cells [3]. Rate-based neural field models of attractor networks predict the emergence of stable, stationary patterns $[2,4]$, whereas simulations of integrate and fire neurons suggest a more complicated dynamical picture. In particular, synaptic timescales appear to play a crucial role $[5,6]$ in that fast synapses tend to lead to transient, local synchronous activity, thus destabilizing activity patterns. Recent work on a model of V1 suggests that such "multiple firing events" (MFEs) may be a generic, emergent feature of spiking networks [7]. In this work, we investigate whether and how MFEs may affect pattern stability in continuous attractor networks. While the stability of spiking neuron-based attractor networks have been studied previously [5,6], the models studied to date contain neither seperate excitatory and inhibitory populations nor a mixture of synaptic timescales (as would be expected in more realistic settings), and the effects of these features on pattern stability are not known.

To investigate these questions, we have implemented continuous attractor networks in both one and two

\footnotetext{
* Correspondence: dlyttle@math.arizona.edu

'Program in Applied Mathematics, University of Arizona, Tucson, AZ 85721, USA

Full list of author information is available at the end of the article
}

dimensions using spiking, integrate-and-fire neurons with conductance-based synapses and seperate excitatory and inhibitory populations. Through simulations, we systematically assess the effect of MFEs on the formation and stability of spatiotemporal activity patterns ("bumps" and "grids"). We also investigate the effects of multiple synaptic timescales, noise, and network heterogeneity on the stability of these patterns. An overarching goal of this work is to obtain insights into how real neural systems might maintain stable persistent activity states, such as those needed for accurately integrating sensorimotor information. Furthermore, as 2-D attractor networks have been incorporated into a number of recent grid cell models $[2,8]$, and the stability of grid cell activity may have a significant effect on place fields [9], understanding the stability of the grid patterns formed by these networks is highly relevant to studies of the rat spatial navigation system.

\section{Author details \\ 'Program in Applied Mathematics, University of Arizona, Tucson, AZ 85721, USA. ${ }^{2}$ Department of Mathematics, University of Arizona, Tucson, AZ 85721, USA. ${ }^{3}$ Department of Psychology, University of Arizona, Tucson, AZ 85721, USA. ${ }^{4}$ Department of Computer Science and Engineering, University of South Florida, Tampa, FL 33620, USA.}

Published: 8 July 2013

\section{References}

1. Compte A, Brunel N, Goldman-Rakic PS, Wang XJ: Synaptic mechanisms and network dynamics underlying spatial working memory in a cortical network model. Cereb Cortex 2000, 10(9):910-923.

2. Burak Y, Fiete IR: Accurate path integration in continuous attractor network models of grid cells. PLoS Comput Biol 2009, 5(2):e1000291.

3. Hafting T, Fyhn M, Molden S, Moser MB, Moser El: Microstructure of a spatial map in the entorhinal cortex. Nature 2005, 436(7052):801-806.

4. Amari S: Dynamics of pattern formation in lateral-inhibition type neural fields. Biol Cybern 1977, 27(2):77-87. 
5. Laing CR, Chow CC: Stationary bumps in networks of spiking neurons. Neural Comput 2001, 13(7):1473-1494.

6. Usher M, Stemmler M, Koch C, Olami Z: Network Amplification of Local Fluctuations Causes High Spike Rate Variability, Fractal Firing Patterns and Oscillatory Local-Field Potentials. Neural Comput 1994, 6(5):795-836.

7. Rangan AV, Young LS: Dynamics of spiking neurons: between homogeneity and synchrony. J Comput Neurosci 2012

8. Giocomo LM, Moser MB, Moser El: Computational models of grid cells. Neuron 2011, 71(4):589-603, 9.

9. Lyttle D, Lin KK, Gereke B, Fellous JM: Spatial scale and place field stability in a modular grid-to-place cell model of the dorsoventral axis of the hippocampus. Submitted 2013.

doi:10.1186/1471-2202-14-S1-P241

Cite this article as: Lyttle et al:: The influence of multiple firing events on the formation and stability of activity patterns in continuous attractor networks. BMC Neuroscience 2013 14(Suppl 1):P241.

\section{Submit your next manuscript to BioMed Central} and take full advantage of:

- Convenient online submission

- Thorough peer review

- No space constraints or color figure charges

- Immediate publication on acceptance

- Inclusion in PubMed, CAS, Scopus and Google Scholar

- Research which is freely available for redistribution

Submit your manuscript at www.biomedcentral.com/submit
C Biomed Central 